\title{
Calibration and Laboratory Test of the Department of Energy Cloud Particle Imager
}

GM McFarquhar

J Um

February 2012 


\section{DISCLAIMER}

This report was prepared as an account of work sponsored by the U.S. Government. Neither the United States nor any agency thereof, nor any of their employees, makes any warranty, express or implied, or assumes any legal liability or responsibility for the accuracy, completeness, or usefulness of any information, apparatus, product, or process disclosed, or represents that its use would not infringe privately owned rights. Reference herein to any specific commercial product, process, or service by trade name, trademark, manufacturer, or otherwise, does not necessarily constitute or imply its endorsement, recommendation, or favoring by the U.S. Government or any agency thereof. The views and opinions of authors expressed herein do not necessarily state or reflect those of the U.S. Government or any agency thereof. 


\section{Calibration and Laboratory Test of the Department of Energy Cloud Particle Imager}

GM McFarquhar

$\mathrm{J}$ Um

February 2012

Work supported by the U.S. Department of Energy,

Office of Science, Office of Biological and Environmental Research 


\section{Contents}

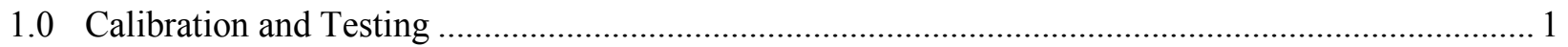

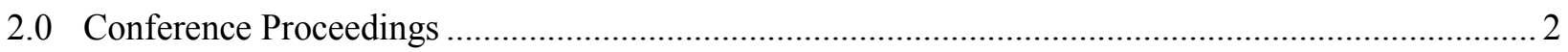




\subsection{Calibration and Testing}

Connolly et al. (2007) identified two problems with the standard Cloud Particle Imager (CPI) processing algorithm provided by Stratton Park Engineering Company Inc.: (1) the particle size extracted from CPI images is larger than the actual particle size, and (2) particles lying a distance greater than the depth of field (DOF) from the object plane are rejected. Connolly et al. (2007) developed an improved calibration method for the CPI version 1.0. However, it cannot be applied to every CPI because different versions of the CPI have differing optical alignment and detection characteristics.

Thus, calibration parameters from the Connolly et al. (2007) algorithm cannot be applied to the Department of Energy's (DOE) CPI because the DOE CPI is version 2.0. Thus, Dr. Junshik Um and Prof. Greg McFarquhar brought the DOE CPI to the University of Manchester, UK, where facilities for calibrating it were available. In addition, two other versions of CPIs (1.0 and 1.5) were available on-site at the University of Manchester so that an intercomparison of three different versions of the CPI was possible.

The three CPIs (versions 1.0, 1.5, and 2.0) were calibrated by moving glass calibration beads and ice analogues of known size parallel to the object plane. The distance between the object plane and a particle, the particle's focus, its apparent maximum dimension, and a background image were measured in order to derive calibration parameters for each CPI version. The calibration parameters are used in two empirical equations that are applied to in situ CPI data to determine particle size and depth of field, and hence particle size distributions (PSDs). After the tests with the glass calibration beads to derive the calibration parameters, the three CPIs were installed at the base of the Manchester Ice Cloud Chamber and connected to air pumps that drew cloud through the sample volume. Warm liquid clouds at a temperature of $1-2^{\circ} \mathrm{C}$ and ice clouds at a temperature of $-5^{\circ} \mathrm{C}$ were generated, and the resulting PSDs for each of the CPIs were determined by applying the results of each calibration.

Our analysis of the data collected during our trip to Manchester revealed that a different calibration equation from that used by Connolly et al. (2007) is required to provide an adequate calibration for all three versions of the CPI. Thus, we have modified the original calibration method of Connolly et al. (2007) and derived new empirical calibration equations. Before applying the calibration, all CPIs showed more than a $10 \%$ overestimation in sizing particles, which became less than $1 \%$ after applying the calibration. We are now applying the calibration to the CPI data collected during the cloud chamber experiment, from which we will be able to derive the PSDs. This last step is important to test the consistency of the calibration across different versions of CPIs, and is a necessary step before finalizing and publishing the calibration method.

We showed preliminary results of our findings at the $13^{\text {th }}$ American Meteorological Society's Conference on Cloud Physics in 2010 (Um et al. 2010). Final results will be presented at the upcoming 2012 International Conference on Clouds and Precipitation in Leipzig, Germany (Um et al. 2012a). A paper describing the calibration procedure and results will be submitted to the Journal of Atmospheric and Oceanic Technology within two months (Um et al. 2012b), after which the newly derived calibration parameters and methods will be made available so that improved PSDs can be generated for past or future field campaigns in which the DOE CPI participated. In particular, it should be possible to apply these calibrations to data collected during the 2006 TWP-ICE and 2008 ISDAC campaigns. 


\subsection{Conference Proceedings}

Um, J, GM McFarquhar, PJ Connolly, C Emersic, Z Ulanowski, and M Gallagher. 2010. "Intercomparison of the performance of three different versions of Cloud Particle Imagers (CPIs)." $13^{\text {th }}$ Conference on Cloud Physics, American Meteorological Society, Portland, Oregon.

Um, J, GM McFarquhar, PC Connolly, C Emersic, Z Ulanowski, and M Gallagher. 2012a. "Calibration of three generations of Cloud Particle Imagers (CPIs) to improve measurements of particle size distributions." International Conference on Clouds and Precipitation, Leipzig, Germany, submitted.

Um, J, GM McFarquhar, PC Connolly, C Emersic, Z Ulanowski, and M Gallagher. 2012b. "Calibration of three generations of Cloud Particle Imagers (CPIs) to improve measurements of particle size distributions." Journal of Atmospheric and Oceanic Technology, in preparation. 


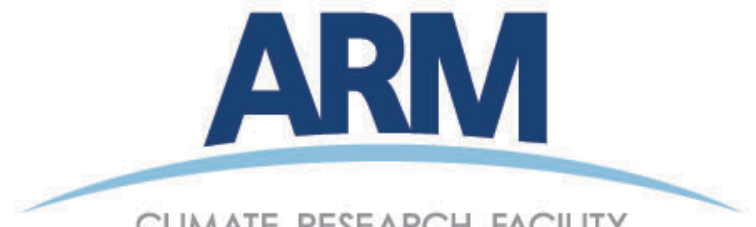

CLIMATE RESEARCH FACILITY

www.arm.gov

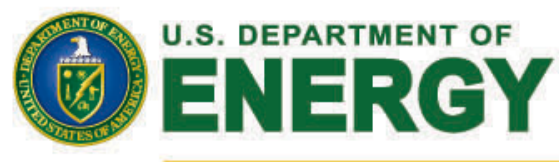

Office of Science 